\title{
COMPORTAMENTO INGESTIVO DE OVINOS ALIMENTADOS COM CANA-DE-AÇÚCAR ENSILADA COM ÓXIDO DE CÁLCIO OU UREIA*
}

\author{
Alberti Ferreira Magalhães ${ }^{1}$, AuREliano José VieIra Pires ${ }^{2}$, Fabiano Ferreira da Silva ${ }^{2}$, Gleidson

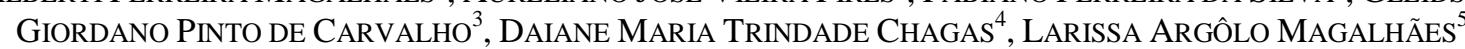 \\ ${ }^{1}$ Pesquisador Doutor da Comissão Executiva do Plano da Lavoura Cacaueira, Centro de Pesquisas do Cacau, Ilhéus, BA, Brasil - \\ alberti300@yahoo.com.br \\ ${ }^{2}$ Professor Doutor da Universidade Estadual do Sudoeste da Bahia, Itapetinga, BA, Brasil \\ ${ }^{3}$ Professor Doutor da Universidade Federal da Bahia, Salvador, BA, Brasil \\ ${ }^{4}$ Pós-graduanda da Universidade Estadual do Sudoeste da Bahia, Itapetinga, BA, Brasil \\ ${ }^{5}$ Graduanda da Universidade Estadual de Santa Cruz, Ilhéus, BA, Brasil \\ * Projeto financiado pelo CNPq
}

\begin{abstract}
Avaliou-se o comportamento ingestivo de ovinos alimentados com cana-de-açúcar ensilada com óxido de cálcio ou ureia. Foram utilizados 20 cordeiros Santa Inês, castrados, distribuídos em um delineamento inteiramente casualizado, alojados em baias individuais. Utilizaram-se quatro tratamentos com óxido de cálcio $(0,0 ; 0,8 ; 1,6$ e 2,4\%) e um com ureia $(1,5 \%)$, ambos na matéria natural. Não foi observada diferença para consumo em kg de MS e FDN/dia. Verificou-se que a alimentação em minutos/dia e minutos/kg de MS e FDN de alimentação e ruminação foram semelhantes. Houve efeito linear para a mastigação em horas/dia e para ócio em minutos/dia, entre as doses de óxido
\end{abstract}

de cálcio. A eficiência de alimentação e ruminação (g de MS e FDN/hora) não apresentou efeito significativo. Não houve diferença para alimentação, ruminação e ócio, número de períodos/dia e para alimentação e ruminação do tempo gasto por período (minutos). Entretanto, houve efeito linear crescente para o ócio. O consumo médio/período de alimentação em kg de MS e FDN não apresentaram diferença. Silagem de cana-de-açúcar com óxido de cálcio ou ureia, fornecidos a ovinos, não afetam os períodos de alimentação e ruminação dos animais, bem como diminuem a ruminação e mastigação e aumenta o ócio.

PALAVRAS-CHAVE: consumo; eficiência de alimentação; ingestão; ruminação.

\section{INGESTIVE BEHAVIOR OF SHEEP FED SUGAR CANE ENSILED WITH UREA OR CALCIUM OXIDE}

\section{ABSTRACT}

We evaluated the ingestive behavior of sheep fed sugar cane ensiled with urea or calcium oxide. We used 20 Santa Ines castrated lambs, distributed into a completely randomized design, housed in individual boxes. We used four treatments with calcium oxide $(0.0,0.8,1.6$ and $2.4 \%)$ and urea $(1.5 \%)$, both on natural materials. No difference was observed for intake in $\mathrm{kg}$ of DM and NDF/day. It was found that the feed in minutes/day and minute/kg of DM and NDF feeding and rumination were similar. There was a linear effect for chewing in hours/day and for resting in minutes/day, among doses of calcium oxide. The efficiency of feeding and rumination (g DM and NDF/hour) presented no significant effect. There was no difference in feeding, rumination and resting, number of periods/day, and feeding and rumination, for a period of time spent (minutes). However, there was increased linear effect for resting. The average intake/feeding period in kg DM and NDF did not show difference. Sugar cane silage with calcium oxide or urea provided to sheep does not affect the periods of feeding and rumination of the animals, as well as it decreases rumination and chewing and increases resting.

KEYWORDS: eating; feeding efficiency; intake; rumination.

Ci. Anim. Bras., Goiânia, v.13, n.1, p. 57 - 66, jan./mar. 2012 


\section{INTRODUÇÃO}

O valor nutritivo de diferentes volumosos pode ser melhorado com a utilização de aditivos, como tem sido mostrado por tratamentos químicos (SANTOS et al., 2004). Vários aditivos têm sido utilizados na ensilagem de cana-de-açúcar com bons resultados (FREITAS, et al., 2006; BALIEIRO NETO et al., 2007). Dentre os diversos aditivos utilizados, verificase que o óxido de cálcio pode reduzir os constituintes da parede celular, preservar os nutrientes solúveis e diminuir perdas do valor nutritivo da cana-de-açúcar (BALIEIRO NETO et al., 2007).

Verifica-se que o conhecimento das atividades realizadas, como comportamento ingestivo (alimentação, ruminação e ócio), e dos hábitos alimentares contribui para a melhoria do bem-estar e do desempenho dos animais que são mantidos em confinamento, como também dos que estão em pastejo (BRÂNCIO et al., 2003; MENDONÇA et al., 2004; TREVISAN et al., 2005).

O comportamento ingestivo pode propiciar perspectiva para o modelo convencional de abordagem zootécnica, de forma a melhorar a qualidade do alimento, implicando em ponderações de ações de manejo, tornando-se uma importante ferramenta de gestão do animal. Tal ferramenta possibilitará a abertura de novos horizontes, trazendo inovações a situações ainda não consideradas ou mal compreendidas, quanto às práticas de manejo (SILVA et al., 2004). Poderá também ser utilizado como ferramenta para avaliação de dietas, possibilitando ajustar o manejo alimentar dos animais para obtenção de melhor desempenho (MENDONÇA et al., 2004).

Tem-se verificado que animais confinados tendem a consumir elevada quantidade de concentrados para suprir a demanda energética e proteica para manutenção e produção (CARVALHO et al., 2008). Dessa forma, o estudo do comportamento ingestivo pode ser utilizado como ferramenta para explicar parte das variações na ingestão de alimento (PEREIRA et al., 2007), visto que, associada ao concentrado, a cana-deaçúcar é utilizada para suplementação nutricional na época seca, sendo uma alternativa para minimizar a perda de peso ou favorecer o ganho (FERNANDES et al., 2003). Entretanto, pelo seu baixo teor de proteína bruta, fibra de degradação ruminal lenta e elevado teor de fibra não-degradável, ocorre limitação na ingestão (PEREIRA et al., 2001).

Este trabalho foi realizado com o objetivo de avaliar o comportamento ingestivo de ovinos recebendo cana-de-açúcar ensilada com dose de óxido de cálcio ou ureia como parte da dieta.

\section{MATERIAL E MÉTODOS}

O experimento foi conduzido no setor de ovinocultura, Ensaios Nutricionais de Ovinos e Caprinos, e no Laboratório de Forragicultura e Pastagens da Universidade Estadual do Sudoeste da Bahia, no Campus de Itapetinga, BA.

Foi utilizado o delineamento inteiramente casualizado (DIC) com cinco tratamentos, sendo quatro com doses de 0,$0 ; 0,8 ; 1,6$ e 2,4\% de óxido de cálcio $(\mathrm{CaO})$ e um tratamento com $1,5 \%$ de ureia, ambos na matéria natural da cana-de-açúcar. Todos os aditivos foram aplicados no momento da ensilagem, com oito repetições por tratamento.

As baias foram providas de comedouros e bebedouros, dispostos frontalmente, com $1,5 \mathrm{~m}^{2}$, e os animais foram alimentados com dieta contendo $70 \%$ da silagem de cana-de-açúcar com óxido de cálcio ou ureia e $30 \%$ de concentrado (Tabela 1). A composição das dietas encontra-se na Tabela 2.

Para confecção das silagens, a cana-de-açúcar de variedade RB 72-454 foi picada, em uma picadeira de forragem convencional, padronizando as partículas com tamanho de 1 a $2 \mathrm{~cm}$, misturada em piso de alvenaria para uma completa homogeneização.

Tabela 1 - Composição percentual dos ingredientes do concentrado e das dietas (\% da matéria seca)

\begin{tabular}{lcccc}
\hline Ingrediente & \multicolumn{2}{c}{ Concentrado } & \multicolumn{2}{c}{ Dieta } \\
\cline { 2 - 5 } & $\begin{array}{c}\text { Silagem de cana } \\
\text { com CaO }\end{array}$ & $\begin{array}{c}\text { Silagem de cana } \\
\text { com ureia }\end{array}$ & $\begin{array}{c}\text { Silagem de cana } \\
\text { com CaO }\end{array}$ & $\begin{array}{c}\text { Silagem de cana } \\
\text { com ureia }\end{array}$ \\
\hline Silagem de cana-de-açúcar & - & - & 70,00 & 70,0 \\
Milho & 56,67 & 65,66 & 17,00 & 19,71 \\
Farelo de soja & 26,67 & 27,70 & 8,00 & 8,29 \\
Ureia & 10,00 & ----- & 3,00 & --- \\
Sal comum & 3,33 & 3,32 & 1,00 & 1,00 \\
Sal mineral $^{2}$ & 3,33 & 3,32 & 1,00 & 1,00 \\
Total $^{1}$ & 100,00 & 100,00 & 100,00 & 100,00 \\
\hline
\end{tabular}

/ cana-de-açúcar com diversas doses de óxido de cálcio ou ureia.

2/ Quantidade por kg do produto: $\mathrm{Ca}=155 \mathrm{~g} ; \mathrm{P}=65 \mathrm{~g} ; \mathrm{S}=12 \mathrm{~g} ; \mathrm{Mg}=6 \mathrm{~g} ; \mathrm{Na}=115 \mathrm{~g} ; \mathrm{Co}=175 \mathrm{mg} ; \mathrm{Cu}=100 \mathrm{mg} ; \mathrm{I}=175 \mathrm{mg}$; $\mathrm{MN}=1400 \mathrm{mg} ; \mathrm{Ni}=42 \mathrm{mg} ; \mathrm{Se}=27 \mathrm{mg} ; \mathrm{Zn}=6000 \mathrm{mg} ; \mathrm{Fe}=1000 \mathrm{mg}$. 
A silagem de cana-de-açúcar, nos tratamentos com $\mathrm{CaO}$, no momento do fornecimento aos animais, foi corrigida para $1 \%$ de ureia (mistura de ureia + sulfato de amônio) na relação 9:1. As dietas foram calculadas com base no NRC (2006), para permitir que houvesse nutrientes (NDT e PB) suficientes para um ganho de peso de $150 \mathrm{~g} / \mathrm{dia}$. Elas foram balanceadas para conterem aproximadamente $13 \%$ de proteína bruta.

O experimento durou 77 dias, constituídos de três períodos experimentais, composto de 21 dias cada um, e ainda um período de 14 dias destinado à adaptação dos animais. No terceiro período experimental, foram realizadas coletas de fezes diretamente do reto do animal durante cinco dias.

As dietas experimentais foram fornecidas à vontade, duas vezes por dia, às $7 \mathrm{~h} 00$ e às $15 \mathrm{~h} 00$, de forma que as mesmas foram ajustadas para manter sobras de aproximadamente $10 \%$ do fornecido (Tabela 2). A composição química da cana-de-açúcar com ureia e óxido de cálcio, calculada para ser isoproteica, está disposta na Tabela 3. As avaliações bromatológicas das dietas experimentais e das amostras de cana-de-açúcar ensilada com óxido de cálcio ou com ureia foram realizadas conforme SILVA \& QUEIROZ (2002).

Tabela 2 - Composição bromatológica das dietas experimentais

\begin{tabular}{lccccc}
\hline \multirow{2}{*}{ Item } & \multicolumn{3}{c}{$\begin{array}{c}\text { Silagem de cana-de-açúcar com CaO } \\
(\% \text { matéria natural })\end{array}$} & \multirow{2}{*}{$\begin{array}{c}\text { Silagem de cana-de- } \\
\text { açúcar com ureia }\end{array}$} \\
\cline { 2 - 4 } & 0,0 & 0,8 & 1,6 & 2,4 & 41,5 \\
\hline Matéria seca (\%) & 41,1 & 42,6 & 43,2 & 43,2 & 14,8 \\
Proteína bruta $^{2}$ & 14,6 & 14,7 & 14,6 & 14,5 & 51,2 \\
FDN $^{2}$ & 55,7 & 49,9 & 42,5 & 37,9 & 53,6 \\
NDT $^{2,3}$ & 50,6 & 58,9 & 60,8 & 64,3 & \\
\hline
\end{tabular}

${ }^{1}$ cana-de-açúcar adicionada de 1,5\% de ureia (\% matéria natural).

${ }^{2}$ base da matéria seca;

${ }^{3}$ estimado segundo NRC (2006).

FDN: fibra em detergente neutro; FDA: fibra em detergente ácido; NDT: nutrientes digestíveis totais.

Para avaliar o comportamento ingestivo, os animais foram submetidos a períodos de observação visual, durante um dia do período experimental, determinando-se o comportamento alimentar durante 24 horas/dia, de acordo com FISCHER et al. (1998). O tempo despendido para alimentação, ruminação e ócio foi submetido a períodos de observação visual para avaliar o comportamento ingestivo durante um dia, na última semana do período experimental. Neste experimento, os animais foram observados durante 24 horas, em intervalos de 5 minutos, para a avaliação dos tempos de alimentação, ruminação e ócio. Durante a observação noturna, o ambiente foi mantido com iluminação artificial. Três dias antes da avaliação, foi fornecida luz artificial para adaptação.

No dia seguinte, foi realizada a contagem do número de mastigações merícicas e do tempo despendido na ruminação de cada bolo ruminal com a utilização de cronômetro digital. Durante a avaliação, foram feitas observações de três bolos ruminais em três períodos diferentes do dia (10-12h; 14-16h e 19-21h), calculando-se a média do número de mastigações merícicas e o tempo gasto por bolo ruminal. Para estimação das variáveis comportamentais, alimentação e ruminação ( $\mathrm{min} / \mathrm{kg}$ MS e FDN), eficiência alimentar ( $g$ MS e FDN/hora), eficiência em ruminação ( $g$ de MS e FDN/bolo e g MS e FDN/hora) e consumo médio de MS e FDN por período de alimentação, considerouse o consumo voluntário de MS e FDN do $17^{\circ}$ e $18^{\circ}$ dias do período experimental, sendo as sobras computadas entre o $17^{\circ}$ e $18^{\circ}$ dias. 
Tabela 3 - Composição bromatológica da silagem de cana-de-açúcar com óxido de cálcio $(\mathrm{CaO})$ ou ureia

\begin{tabular}{lccccc}
\hline \multirow{2}{*}{\multicolumn{1}{c}{ Item }} & \multicolumn{4}{c}{$\begin{array}{c}\text { Silagem de cana-de-açúcar com CaO (\% matéria } \\
\text { natural) }\end{array}$} & $\begin{array}{c}\text { Silagem de cana-de- } \\
\text { açúcar com ureia }\end{array}$ \\
\cline { 2 - 5 } & 0,0 & 0,8 & 1,6 & 2,4 & 20,7 \\
\hline Matéria seca (\%) $^{*} 20,1$ & 22,3 & 23,1 & 23,2 & 14,9 \\
Proteína bruta $^{1}$ & 1,15 & 1,23 & 1,15 & 1,10 & 68,6 \\
Fibra em detergente neutro $^{1}$ & 74,0 & 58,6 & 55,1 & 48,5 & 65,6 \\
FDNcp $^{1}$ & 71,1 & 55,7 & 52,4 & 45,6 & 59,4 \\
Fibra em detergente ácido $^{1}$ & 63,3 & 50,3 & 45,3 & 40,1 & 0,81 \\
PIDN $^{1}$ & 059 & 0,51 & 0,50 & 0,42 & 2,2 \\
CIDN $^{1}$ & 2,4 & 2,4 & 2,3 & 2,5 & 1,8 \\
Extrato etéreo $^{1}$ & 1,6 & 1,8 & 1,8 & 1,8 & 45,1 \\
Celulose $^{1}$ & 49,0 & 40,7 & 33,1 & 31,1 & 9,2 \\
Hemicelulose $^{1}$ & 10,7 & 8,2 & 9,8 & 8,4 & 9,5 \\
Lignina $^{1}$ & 10,3 & 8,4 & 6,8 & 5,7 & 3,3 \\
Cinza $^{1}$ & 3,6 & 8,1 & 10,0 & 14,0 & 59,6 \\
DISMS $^{1}$ & 51,2 & 51,1 & 61,1 & 65,5 & 47,0 \\
Nutrientes digestíveis totais $^{2}$ & 42,8 & 54,6 & 57,3 & 62,3 & \\
\hline
\end{tabular}

1/ Valores em percentagem da matéria seca. ${ }^{2} /$ Estimativa segundo o NRC (2006). Proteína indigestível em detergente neutro (PIDN), cinza indigestível em detergente neutro (CIDN), fibra em detergente neutro corrigido para cinza e proteína (FDNcp), digestibilidade in situ da matéria seca (DISMS).

O número de bolos ruminados diariamente foi obtido dividindo-se o tempo total de ruminação (minuto), pelo tempo médio gasto na ruminação de um bolo. As concentrações de MS e FDN em cada bolo (g) ruminado foram obtidas a partir da divisão da quantidade de MS e FDN, consumida (g/dia) pelo número de bolos ruminados diariamente.

A eficiência de alimentação e ruminação foi obtida utilizando-se o seguinte método:

$$
\begin{aligned}
\text { EALMS } & =\mathrm{CMS} / \mathrm{TAL} ; \\
\mathrm{EALFDN} & =\mathrm{CFDN} / \mathrm{TAL} ;
\end{aligned}
$$

em que: EALMS (g de MS consumida/h); EALFDN (g FDN consumida/h) = eficiência de alimentação; CMS $(\mathrm{g})=$ consumo diário de matéria seca; CFDN $(\mathrm{g})=$ consumo diário da FDN; TAL = tempo gasto diariamente em alimentação.

$$
\begin{aligned}
\text { ERUMS } & =\mathrm{CMS} / \mathrm{TRU} ; \\
\mathrm{ERUFDN} & =\mathrm{CFDN} / \mathrm{TRU} ;
\end{aligned}
$$

em que: ERUMS (g MS ruminal/h); ERUFDN (g da FDN ruminal/h) $=$ eficiência de ruminação e TRU $(\mathrm{h} /$ dia $)=$ tempo de ruminação.

$$
\mathrm{TMT}=\mathrm{TAL}+\mathrm{TRU}
$$

em que: TMT (minuto/dia) $=$ tempo de mastigação total.
Esses procedimentos foram obtidos pela metodologia descrita por BÜRGER et al. (2000).

O número de períodos de alimentação, ruminação e ócio foram contabilizados pelo número de sequências de atividade observadas na planilha de anotações. A duração média diária desses períodos de atividades foi calculada dividindo-se a duração total de cada atividade (alimentação, ruminação e ócio em $\mathrm{min} / \mathrm{dia}$ ) pelo seu respectivo número de períodos discretos. Os resultados foram submetidos à análise de variância, procedendo-se posteriormente ao teste Dunnett para avaliar o efeito das doses de óxido de cálcio em relação à ureia (testemunha) e à análise de regressão para o estudo do efeito das doses de $\mathrm{CaO}$, a $5 \%$ de probabilidade. Foi utilizado o programa SAEG - Sistema de Análises Estatísticas e Genéticas da UFV (RIBEIRO JR., 2001).

\section{RESULTADOS E DISCUSSÃO}

O consumo de matéria seca (MS) e fibra em detergente neutro (FDN) $(\mathrm{kg})$ não foi afetado $(\mathrm{P}>0,05)$ pela utilização da silagem de cana-deaçúcar com óxido de cálcio $(\mathrm{CaO})$ em relação à 
silagem com ureia no período de 24 horas (Tabela 4).

As atividades de alimentação e ruminação em minutos/dia, minutos/kg de MS e minutos/kg de FDN não apresentaram diferença $(\mathrm{P}>0,05)$ entre a silagem de cana-de-açúcar com óxido de cálcio e a silagem com ureia. Não houve efeito $(\mathrm{P}>0,05)$ das doses com óxido de cálcio na silagem de cana-deaçúcar.

Não houve diferença $(\mathrm{P}>0,05)$ da silagem de cana-de-açúcar com óxido de cálcio em relação à silagem com ureia para a mastigação em número de bolo, segundo/bolo, $\mathrm{n}^{\%} / \mathrm{dia}$ e minutos/kg de MS e FDN. As doses de óxido de cálcio na silagem de cana-de-açúcar não produziram efeito $(\mathrm{P}>0,05)$ sobre as variáveis citadas anteriormente (Tabela 4).

Alguns fatores podem afetar a ingestão de alimentos, como altos níveis de FDN. Esse fato foi observado nos valores das dietas experimentais em que houve diminuição do FDN com o aumento das doses de $\mathrm{CaO}$. Diferenças significativas nessas variáveis seriam esperadas, caso o tempo de alimentação, ruminação e o tempo de mastigação de MS e FDN fossem influenciados pelo aumento das doses de óxido de cálcio. Embora o teor de FDN nas dietas (Tabela 2) tenha diminuído com o aumento das doses de óxido de cálcio, estas não foram suficientes para provocar alterações nas atividades do consumo. CARDOSO et al. (2006) não observaram diferença nos tempos de ingestão, ruminação e mastigação em função do nível de FDN em dietas de cordeiros quando esse nível é inferior a $44 \%$, o que contraria as constatações feitas por MERTENS (1996) de que há alterações significativas em dietas com diferentes níveis de FDN e por VAN SOEST (1994) de que, ao elevar o nível de FDN da dieta, há aumento no tempo despendido com ruminação, sendo esse tempo gasto proporcional ao teor da parede celular.

TABELA 4 - Consumos de matéria seca (CMS) e consumo de fibra em detergente neutro (CFDN), das atividades de alimentação, ruminação e ócio e coeficiente de variação $(\mathrm{CV})$ de ovinos alimentados com silagem de cana-de-açúcar com óxido de cálcio $(\mathrm{CaO})$ ou ureia

\begin{tabular}{|c|c|c|c|c|c|c|c|}
\hline \multirow{2}{*}{ Item } & \multicolumn{4}{|c|}{$\begin{array}{c}\text { Silagem de cana-de-açúcar com } \mathrm{CaO} \\
(\% \text { matéria natural })\end{array}$} & \multirow{2}{*}{$\begin{array}{l}\text { Silagem } \\
\text { de cana- } \\
\text { de-açúcar } \\
\text { com ureia }{ }^{1}\end{array}$} & \multirow{2}{*}{$\mathrm{CV}(\%)^{2}$} & \multirow{2}{*}{ Equação } \\
\hline & 0 & 0,8 & 1,6 & 2,4 & & & \\
\hline & \multicolumn{4}{|c|}{ Consumo em 24 horas (kg) } & & & \\
\hline MS & 0,577 & 0,727 & 0,622 & 0,553 & 0,643 & 20,3 & $\hat{Y}=0,620$ \\
\hline \multirow[t]{2}{*}{ FDN } & 0,291 & 0,294 & 0,319 & 0,277 & 0,319 & 14,6 & $\hat{Y}=0,295$ \\
\hline & \multicolumn{4}{|c|}{ Alimentação } & & & \\
\hline Min/dia & 391,25 & 347,50 & 308,75 & 273,75 & 378,75 & 24,8 & $\hat{Y}=330,4$ \\
\hline $\mathrm{Min} / \mathrm{kg} \mathrm{MS}$ & 708,08 & 474,07 & 565,90 & 502,82 & 607,12 & 36,2 & $\hat{Y}=562,7$ \\
\hline $\mathrm{Min} / \mathrm{kg}$ FDN & 1430,39 & 1169,39 & 975,17 & 986,85 & 1231,02 & 32,6 & $\hat{Y}=1140,5$ \\
\hline \multicolumn{8}{|c|}{ Ruminação } \\
\hline Min/dia & 553,75 & 465,00 & 380,00 & 383,75 & 511,25 & 20,6 & $\hat{Y}=445,7$ \\
\hline $\mathrm{Min} / \mathrm{kg} \mathrm{MS}$ & 1003,19 & 640,78 & 696,27 & 709,75 & 803,58 & 32,2 & $\hat{Y}=762,5$ \\
\hline $\mathrm{Min} / \mathrm{kg}$ FDN & 2022,78 & 1585,77 & 1206,76 & 1388,11 & 1626,85 & 26,7 & $\hat{\mathrm{Y}}=1550,9$ \\
\hline \multicolumn{5}{|c|}{ Mastigação } & & & \multirow{3}{*}{$\begin{array}{l}\hat{Y}=67,3 \\
\hat{Y}=48,6\end{array}$} \\
\hline N\%/bolo & 66,00 & 68,25 & 66,00 & 68,75 & 63,50 & 22,6 & \\
\hline Seg/bolo & 45,14 & 49,19 & 48,42 & 51,64 & 45,64 & 16,5 & \\
\hline No/dia & 49051 & 39251 & 31671 & 30249 & 42133 & 27,1 & \multirow{6}{*}{$\begin{array}{c}\hat{\mathrm{Y}}=48088,8 \\
\hat{\mathrm{Y}}=15,3979-2,05469 \mathrm{CaO}^{* *}\left(\mathrm{r}^{2}=0,94\right) \\
\hat{\mathrm{Y}}=1325,3 \\
\hat{\mathrm{Y}}=2691,3 \\
\hat{\mathrm{Y}}=516,125+123,281 \mathrm{CaO} * *\left(\mathrm{r}^{2}=0,94\right)\end{array}$} \\
\hline Horas/dia & 15,75 & 13,54 & 11,48 & $10,96^{*}$ & 14,83 & 15,2 & \\
\hline $\mathrm{Min} / \mathrm{kg} \mathrm{MS}$ & 1711,27 & 1114,85 & 1262,18 & 1212,57 & 1410,70 & 30,4 & \\
\hline Min/kg FDN & 3453,17 & 2755,17 & 2181,93 & 2374,96 & 2857,87 & 24,7 & \\
\hline \multicolumn{5}{|c|}{ Ócio } & & & \\
\hline Min/dia & $495,00 *$ & $627,50^{*}$ & $751,25 *$ & $785,50 *$ & 550,0 & 19,0 & \\
\hline
\end{tabular}

* Médias seguidas por asterisco diferem da testemunha a 5\% de probabilidade pelo teste Dunnett. 1 / cana-de-açúcar adicionada de $1,5 \%$ de ureia (\% matéria natural). ${ }^{2} /$ Coeficiente de variação. (ns) não significativo; (*) significativo a $5 \%$ e (**) significativo a $1 \%$ de probabilidade, respectivamente.

É possível que o consumo de MS não tenha sido afetado em função de diversas variáveis como 
palatabilidade e seleção do volumoso e que essas ou outras variáveis podem ter contribuído juntamente com o uso do aditivo e a forma física da dieta.

Houve diferença $(\mathrm{P}<0,05)$ da mastigação em horas/dia da silagem de cana-de-açúcar com óxido de cálcio em relação à silagem com ureia. Houve efeito $(\mathrm{P}<0,05)$ linear decrescente na mastigação (horas/dia) da silagem quanto às doses de óxido de cálcio. Os tempos despendidos em alimentação, ruminação (minutos/dia), bem como os tempos de alimentação e ruminação (minutos/kg de MS e da FDN) verificados neste estudo (Tabela 4) foram maiores que os encontrados por ALVES et al. (2010), que obtiveram uma média de alimentação e ruminação de 317,19 e 468,59 minutos/dia, respectivamente, e média do tempo gasto com o consumo de 256,1 e 599,2 minutos/kg de MS e FDN, respectivamente. Verificou-se que o efeito do óxido de cálcio sobre a cana-de-açúcar ocorreu, possivelmente, em função do aumento das doses de aditivo que, por sua vez, fez com que os animais necessitassem de menos horas por dia para mastigar a silagem à medida que as doses de $\mathrm{CaO}$ foram aumentando. Isso só foi possível pela ação da cal sobre os constituintes da parede celular, que permitiram não só diminuir o FDN (Tabela 2) da dieta experimental, como também a fibra em detergente neutro (FDA) e a lignina (Tabela 3 ).

Houve diferença $(\mathrm{P}<0,05)$ do ócio em minutos/dia na silagem de cana-de-açúcar em relação à silagem com ureia, como também foi verificado efeito $(\mathrm{P}<0,05)$ linear crescente para o tempo despendido com ócio, de acordo com a inclusão do óxido de cálcio na cana-de-açúcar. Os animais alimentados com a silagem de cana-de-açúcar com óxido de cálcio apresentaram valor médio de 641,25 minutos/dia para a atividade de ócio. O menor tempo despendido com ócio mostra que os ovinos tiveram mais tempo para promover a mastigação. À medida que as doses de $\mathrm{CaO}$ aumentaram, mais tempo foi despendido com o ócio, comprovando a hipótese de que o menor teor de FDN na cana-de-açúcar ensilada com maiores doses de $\mathrm{CaO}$ provocou diminuição na mastigação. Fato que foi constatado por MERTENS (1997), que observou que a elevação de quantidade de fibra nas dietas estimula a atividade mastigatória, ratificando os resultados encontrados neste estudo. Da mesma forma, os resultados obtidos por
CARVALHO et al. (2006a), que trabalharam com níveis da FDN (20, 27, 34, 41 e 48\%) provenientes de forragem em dietas para cabras na avaliação do comportamento ingestivo, mostraram aumento nos tempos de ingestão e ruminação e diminuição do tempo de ócio com a elevação dos níveis da FDN na ração. Esses valores são superiores aos encontrados por MACEDO et al. (2007), que avaliaram o comportamento ingestivo de ovinos em dietas contendo bagaço de laranja em substituição à silagem de sorgo, e relataram ponto de mínima de $335,02 \mathrm{~min} / \mathrm{dia}$.

Não houve efeito $(\mathrm{P}>0,05)$ para as atividades de alimentação e ruminação em min/dia. Embora o teor de FDN na silagem de cana-de-açúcar com $\mathrm{CaO}$ tenha decrescido (Tabela 2), não foi suficiente para provocar alterações nas atividades de alimentação e ruminação em min/dia. A silagem com ureia também não provocou alterações nas atividades supracitadas, estando de acordo com os achados de CARDOSO et al. (2006) e CARVALHO et al. (2006a).

Verificou-se, no presente estudo, que foram gastas em média 7,43 horas de ruminação, com $70 \%$ de volumoso e $30 \%$ de concentrado, valores similares aos que foram encontrados por CARVALHO et al. (2004), média de 7,60 horas/dia, ao trabalharem com dieta à base de silagem de milho; por ALVES et al. (2010), 7,81 horas/dia em ovinos com dieta de Tifton 85 como volumoso (40\%) e $60 \%$ de concentrado composto de $30 \%$ de farelo de vagem de algaroba na dieta além dos outros ingredientes; por MACEDO et al. (2007), 8,16 horas/dia, ao estudarem ovinos recebendo dietas com diferentes níveis de bagaço de laranja em substituição à silagem de sorgo; e por MENDES et al. (2010), que obtiveram valores menores (médio de 4,91 horas/dia), quando trabalharam com cordeiros em dieta de bagaço de cana-de-açúcar in natura.

Ainda é possível verificar que os resultados dos tempos desprendidos com mastigação merícicas apresentados neste estudo corroboram os de CARVALHO et al. (2006b) quanto ao $\mathrm{n} / \mathrm{dia}, \mathrm{n} / \mathrm{bolo}$ e horas/dia (com efeito linear). Esses autores avaliaram o comportamento ingestivo de ovinos com dietas compostas de silagem de capim-elefante, amonizado ou não, e subprodutos agroindustriais. VAN SOEST (1994) relata que pequenos ruminantes são especializados na seleção de alimentos, mas 
utilizam mal os carboidratos fibrosos. Possivelmente, o óxido de cálcio não foi eficiente para diferenciar os tempos de ruminação em segundo/bolo, visto que a FDN da silagem de cana-de-açúcar na dieta diminuiu em função das doses de $\mathrm{CaO}$ (Tabela 2).

Não houve diferença $(\mathrm{P}>0,05)$ quanto à eficiência de alimentação e ruminação (Tabela 5) na silagem de cana-de-açúcar com óxido de cálcio em relação à silagem com ureia, como também entre as doses de óxido de cálcio, possivelmente, pela ausência de efeito significativo no consumo de matéria seca observada nas atividades. A ausência do efeito observada nas atividades de alimentação e ruminação pode estar também relacionada com a aproximação entre a composição química das dietas (Tabela 2), em que os tamanhos das partículas dos alimentos apresentaram semelhanças, visto que seu processamento foi o mesmo para todas as dietas experimentais. Esses argumentos são confirmados por VAN SOEST (1994), para quem o tamanho da partícula pode ser um fator importante que influencia o valor nutricional do alimento, pois afeta tanto o consumo de matéria seca quanto a retenção ruminal, e por SAENZ (2005), para quem o tamanho de partículas dos alimentos exerce grande efeito sobre as atividades de ruminação e mastigação.

TABELA 5 - Eficiências de alimentação e ruminação e coeficiente de variação (CV\%) em ovinos alimentados com dietas contendo silagem de cana-de-açúcar com óxido de cálcio $(\mathrm{CaO})$ ou ureia

\begin{tabular}{|c|c|c|c|c|c|c|c|}
\hline \multirow{2}{*}{ Item } & \multicolumn{4}{|c|}{$\begin{array}{c}\text { Silagem de cana-de-açúcar com } \mathrm{CaO}(\% \\
\text { matéria natural) }\end{array}$} & \multirow{2}{*}{$\begin{array}{l}\text { Silagem de } \\
\text { cana-de- } \\
\text { açúcar com } \\
\text { ureia }^{1}\end{array}$} & \multirow{2}{*}{$\begin{array}{l}\mathrm{CV} \\
(\%)^{2}\end{array}$} & \multirow{2}{*}{$\begin{array}{l}\text { Equação de } \\
\text { regressão }\end{array}$} \\
\hline & 0 & 0,8 & 1,6 & 2,4 & & & \\
\hline & \multicolumn{4}{|c|}{ Eficiência de alimentação } & & & \\
\hline g MS/hora & 88,47 & 151,36 & 128,88 & 129,53 & 104,52 & 43,3 & $\hat{\mathrm{Y}}=124,6$ \\
\hline g FDN/hora & 44,54 & 60,80 & 63,97 & 64,40 & 51,84 & 33,5 & $\hat{Y}=58,4$ \\
\hline \multicolumn{8}{|c|}{ Eficiência de ruminação } \\
\hline Bolos (n\%dia) & 745,44 & 570,73 & 478,21 & 461,47 & 689,17 & 25,3 & $\hat{\mathrm{Y}}=564,0$ \\
\hline g MS/bolo & 0,80 & 1,36 & 1,55 & 1,28 & 0,96 & 48,2 & $\hat{Y}=1,25$ \\
\hline g FDN/bolo & 0,40 & 0,55 & 0,75 & 0,62 & 0,48 & 35,3 & $\hat{\mathrm{Y}}=0,58$ \\
\hline g MS/hora & 63,22 & 100,41 & 111,45 & 87,89 & 76,75 & 42,1 & $\hat{\mathrm{Y}}=90,8$ \\
\hline g FDN/hora & 31,74 & 40,56 & 55,13 & 43,61 & 38,02 & 30,5 & $\hat{\mathrm{Y}}=42,8$ \\
\hline
\end{tabular}

Outros resultados de trabalhos com subprodutos e volumosos diferentes da cana-deaçúcar foram relatados por CARVALHO et al. (2006b) e COSTA et al. (2010), que não observaram diferença na eficiência de alimentação em g de MS e FDN/hora com capim-elefante amonizado e não amonizado, com farelo de cacau $40 \%$ e torta de dendê $40 \%$. Observaram-se, neste estudo, valores médios de eficiência de alimentação (EAL), em g de MS/hora e g de FDN/hora, de 120,55 e 57,11, respectivamente (Tabela 5). A média da eficiência de ruminação ERU foi de 589,0 bolos (n\%/dia), 1,19 g MS/bolo, 0,56 g de FDN/bolo, 87,95 $\mathrm{g}$ de MS/hora e 41,81 g de FDN/hora.

Não houve diferença $(\mathrm{P}>0,05)$ nas observações do número de períodos/dia de alimentação, ruminação e ócio nem para o tempo gasto por período (em minutos) de alimentação e ruminação na silagem de cana-de-açúcar com óxido de cálcio em relação à silagem com ureia, como também não houve efeito $(\mathrm{P}>0,05)$ nas silagens com doses de óxido de cálcio. Entretanto, para o tempo gasto por período com ócio, houve efeito $(\mathrm{P}<0,05)$ linear crescente na silagem de cana-de-açúcar para as doses de óxido de cálcio, mas não houve diferença ( $\mathrm{P}>0,05)$ para o tempo gasto por período (minutos) comparando-se a silagem de cana com óxido de cálcio com a silagem com ureia (Tabela 6). O consumo médio por período de alimentação em $\mathrm{kg}$ de MS e FDN foi semelhante $(\mathrm{P}>0,05)$ na silagem de cana-de-açúcar com óxido de cálcio em relação à silagem com ureia. O consumo médio de MS e FDN não foram afetados $(\mathrm{P}>0,05)$ pelas doses de óxido de cálcio na cana-de-açúcar e os valores médios das 
silagens de cana-de-açúcar encontrados foram 0,029 e $0,014 \mathrm{~kg}$ de MS e FDN, respectivamente.

Foi verificado que o número de períodos de alimentação e o tempo médio gasto por período não foram diferentes e não influenciaram no consumo médio por períodos de MS e FDN na silagem de cana-de-açúcar com adição de óxido de cálcio, visto que existe uma relação direta entre as variáveis número de período e tempo gasto, em que o aumento em uma dessas variáveis implica a redução da outra. Os resultados aqui apresentados são concordantes com as constatações feitas por CARVALHO et al. (2006b) que, ao trabalharem com silagem de capimelefante amonizada ou não e subprodutos em dietas para ovinos, observaram que não houve diferença no consumo médio por período de alimentação da MS e FDN.

A ruminação tem por objetivo diminuir o tamanho das partículas dos alimentos para facilitar a degradação, entretanto, o teor de fibra e a forma física das mesmas afetam o tempo de ruminação (VAN SOEST, 1994). As dietas (Tabela 2) apresentaram diminuição da FDN na medida em que se aumentaram as doses de $\mathrm{CaO}$, com o mesmo tamanho das partículas, tanto da cana-de-açúcar (1 a $2 \mathrm{~cm})$ como do concentrado e sua relação volumoso:concentrado, sendo que foi usado apenas um único tipo de volumoso e de concentrado para todos os animais. Foi verificado, então, que a inclusão de ureia na silagem da cana-de-açúcar disponibilizou maior quantidade de nitrogênio para os microrganismos do rúmen, o que aumentou a eficiência microbiana, melhorando a digestibilidade da MS e FDN, e aumentou o consumo médio por período de alimentação, diminuindo o tempo de ruminação que, neste caso, não apresentou diferença entre as silagens pela semelhança entre as dietas, as quais foram isoproteicas. No consumo médio por período, apesar de não ter sido observada diferença entre as silagens e entre os tratamentos com $\mathrm{CaO}$, constatou-se que muitas variações podem ter acontecido, não provocando diferença entre os tratamentos, exatamente em função das variações nos teores de fibra e energia entre as silagens.

Tabela 6 - Número e tempo médio despendido por período nas atividades de alimentação, ruminação e ócio e consumo de MS e FDN por período de alimentação e coeficiente de variação (CV\%) de ovinos alimentados com dietas contendo silagem de cana-de-açúcar com óxido de cálcio $(\mathrm{CaO})$ ou ureia

\begin{tabular}{|c|c|c|c|c|c|c|c|}
\hline \multirow[t]{2}{*}{ Item } & \multicolumn{4}{|c|}{$\begin{array}{c}\text { Silagem de cana-de-açúcar com } \mathrm{CaO} \\
\text { (\% matéria natural) }\end{array}$} & \multirow[t]{2}{*}{$\begin{array}{l}\text { Silagem de } \\
\text { cana-de-açúcar } \\
\text { com ureia }^{1}\end{array}$} & \multirow[t]{2}{*}{$\mathrm{CV}(\%)^{2}$} & \multirow[t]{2}{*}{ Equação } \\
\hline & 0 & 0,8 & 1,6 & 2,4 & & & \\
\hline & \multicolumn{4}{|c|}{ Número de períodos (n\%/dia) } & & & \\
\hline Alimentação & 21,25 & 25,00 & 23,50 & 21,75 & 19,75 & 25,6 & $\hat{\mathrm{Y}}=22,9$ \\
\hline Ruminação & 26,50 & 25,00 & 23,75 & 24,25 & 21,25 & 20,7 & $\hat{\mathrm{Y}}=24,9$ \\
\hline \multirow[t]{2}{*}{ Ócio } & 38,00 & 43,75 & 42,75 & 41,00 & 33,75 & 17,0 & $\hat{Y}=41,4$ \\
\hline & \multicolumn{4}{|c|}{ Tempo gasto por período $(\mathrm{min})$} & & & \\
\hline Alimentação & 19,75 & 13,60 & 13,90 & 12,61 & 19,74 & 28,4 & $\hat{Y}=15,0$ \\
\hline Ruminação & 22,55 & 18,40 & 15,73 & 16,42 & 24,03 & 25,5 & $\hat{Y}=18,3$ \\
\hline \multirow[t]{2}{*}{ Ócio } & 13,48 & 14,40 & 17,50 & 19,24 & 16,68 & 16,2 & $\hat{\mathrm{Y}}=13,0943+2,54869 * * \mathrm{CaO}\left(\mathrm{r}^{2}=0,94\right)$ \\
\hline & \multicolumn{4}{|c|}{$\begin{array}{l}\text { Consumo médio por período de } \\
\text { alimentação }(\mathrm{kg})\end{array}$} & & & \\
\hline MS & 0,029 & 0,031 & 0,026 & $0,0,26$ & 0,034 & 28,4 & $\hat{\mathrm{Y}}=0,028$ \\
\hline FDN & 0,015 & 0,013 & 0,014 & 0,013 & 0,017 & 29,5 & $\hat{\mathrm{Y}}=0,014$ \\
\hline
\end{tabular}

* Médias seguidas de uma mesma letra, em uma mesma linha, não diferem pelo teste Dunnett a 5\% de probabilidade.

$1 /$ cana-de-açúcar adicionada de $1,5 \%$ de ureia (\% matéria natural). ${ }^{2} /$ Coeficiente de variação. (ns) não significativo;

(*) significativo a $5 \%$ e $(* *)$ significativo a $1 \%$ de probabilidade, respectivamente.

\section{CONCLUSÃO}

Silagem de cana-de-açúcar com óxido de cálcio $(0,0 ; 0,8 ; 1,6$ e $2,4 \%)$ ou ureia, quando fornecidos a ovinos, não afetam os tempos de alimentação e ruminação dos animais.
Dietas para ovinos confinados, contendo cana-de-açúcar ensilada com óxido de cálcio em doses de até 2,4\% ou ureia na dose de 1,5\%, diminuem a ruminação e mastigação e aumentam o ócio dos animais.

\section{REFERÊNCIAS}


ALVES, E. M.; PEDREIRA, M. dos S.; OLIVEIRA, C. A. S. de; AGUIAR, L. V.; PEREIRA, M. L. A.; ALMEIDA, P. J. P. Comportamento ingestivo de ovinos alimentados com farelo da vagem de algaroba associado a níveis de ureia. Acta Scientiarum Animal Sciences. v. 32, n. 4, p. 439-445, 2010.

BALIEIRO NETO, G.; SIQUEIRA, G. R.; REIS, R. A.; NOGUEIRA, J. R.; ROTH, M de T. P.; ROTH, A. P. de T. P. Óxido de cálcio como aditivo na ensilagem de canade-açúcar. Revista Brasileira de Zootecnia, v. 36, n. 5, p. 1231-1239, 2007.

BRÂNCIO, P. A.; EUCLIDES, V. P. B.; NASCIMENTO JR. D.; FONSECA, D. M. da; ALMEIDA, R. G. de. MACEDO, M. C. M.; BARBOSA, R. A. Avaliação de três cultivares de Panicum maximum Jacq. sob pastejo: comportamento ingestivo de bovinos. Revista Brasileira de Zootecnia, v. 32, n. 5, p. 1045-1053, 2003.

BÜRGER, P. J.; PEREIRA, J. C.; SILVA, J. F. C.; VALADARES FILHO, S. C.; QUEIROZ, A. C. de; CECON, P. R.; MONTEIRO, H. C. de F. Consumo e digestibilidade aparente total e parcial em bezerros Holandeses alimentados com dietas contendo diferentes níveis de concentrado. Revista Brasileira de Zootecnia, v. 29, n.1, p. 206-214, 2000 (suplemento).

CARDOSO, A. R.; CARVALHO, S.; GALVANI, P. B.; PIRES, C. C.; GASPERIN, B. G.; GARCIA, R. P. A. Comportamento ingestivo de cordeiros alimentados com dietas contendo diferentes níveis de fibra em detergente neutro. Ciência Rural, v. 36, n. 2, p. 604-609, 2006.

CARVAlHO, G. G. P de; PIRES, A. J. V.; SILVA, R. R.; RIBEIRO, L. S. O.; CHAGAS, D. M. T. Comportamento ingestivo de ovinos Santa Inês alimentados com dietas contendo farelo de cacau. Revista Brasileira de Zootecnia, v. 37, n. 4, p. 660-665, 2008.

CARVAlHO, G. G. P. de; PIRES, A. J. V.; SILVA, F. F. da; VELOSO, C. M.; SILVA, R. R.; SILVA, H. G. de O.; BONOMO, P.; MENDONÇA, S. de S. Comportamento ingestivo de cabras leiteiras alimentadas com farelo de cacau ou torta de dendê. Pesquisa Agropecuária Brasileira. v. 39, n. 9, p. 919-925, 2004.

CARVALHO, G. G. P. de; PIRES, A. J. V.; SILVA, R. R.; VElOSO, C. M.; SILVA, H. G. de O. Comportamento ingestivo de ovinos alimentados com dietas compostas de silagem de capim-elefante amonizada ou não e subprodutos agroindustriais. Revista Brasileira de Zootecnia, v. 35, n. 4, p. 1805-1812, 2006b (suplemento).

CARVALHO, S.; RODRIGUES, M. T.; BRANCO, R. H.; RODRIGUES, C. A. F. Comportamento ingestivo de cabras Alpinas em lactação alimentadas com dietas contendo diferentes níveis de fibra em detergente neutro proveniente da forragem. Revista Brasileira de Zootecnia, v. 35, n. 2, p. 562-568, 2006a.

COSTA, M. R. G. F.; CARNEIRO, M. S. de S.; PEREIRA, E. S.; SOUTO, J. S.; MORAIS NETO, L. B. de; REGADA FILHO, J. G. L.; ALENCAR, C. E. M de. Comportamento ingestivo de ovinos Morada Nova recebendo dietas à base de feno de juazeiro. Revista Brasileira de Saúde e Produção Animal, v. 11, n. 4, p. 1012-1022, 2010.

FERNANDES, A. M.; QUEIROZ, A. C. de. PEREIRA, J. C.; LANA, R. de P.; BARBOSA, M. H. P.; FOSENCA, D. M. da; DETMANN, E.; CABRAL, L. da S.; PEREIRA, E. S.; VITTORI, A. Composição químicobromatológica de variedades de cana-de-açúcar (Saccharum spp L.) com diferentes ciclos de produção (precoce e intermediário) em três idades de corte. Revista Brasileira de Zootecnia, v. 32, n. 4, p. 977-985, 2003.

FISCHER, V.; DESWYSEN, A. G.; DÈSPRES, L.; DUTILLEUL, P.; LOBATO, J. F. P. Padrões nectemerais do comportamento ingestivo de ovinos. Revista Brasileira de Zootecnia, v. 27, n. 2, p. 362-369, 1998.

FREITAS, A. W. P.; PEREIRA, J. C.; ROCHA, F. C.; COSTA, M. G.; LEONEL, F de P.; RIBEIRO, M. D. Avaliação da qualidade nutricional da silagem de cana-deaçúcar com aditivos microbianos e enriquecida com resíduo da colheita de soja. Revista Brasileira de Zootecnia, v. 35, n. 1, p. 38-47, 2006.

MACEDO, C. A. B. de; MIZUBUTI, I. Y.; MOREIRA, F. B.; PEREIRA, E. S.; RIBEIRO, E. L. de A.; ROCHA, M. A. da; RAMOS, B. M. de O.; MORI, R. M.; PINTO, A. P.; ALVES, T. C. CASIMIRO, T. R. Comportamento ingestivo de ovinos recebendo dietas com diferentes níveis de bagaço de laranja em substituição à silagem de sorgo na ração. Revista Brasileira de Zootecnia, v. 36, n. 6, p. 1910-1916, 2007.

MENDES, C. Q.; TURINO, V. de F.; SUSIN, I.; PIRES, A. V.; MORAIS, J. B.; GENTIL, R. S. Comportamento ingestivo de cordeiros e digestibilidade dos nutrientes de dietas contendo alta proporção de concentrado e diferentes fontes de fibra em detergente neutro. Revista Brasileira de Zootecnia. v. 39, n. 3, p. 594-600, 2010.

MENDONÇA, S. S.; CAMPOS, J. M. S.; VALADARES FILHO, S. C.; VALADARES, R. F. D.; SOARES, C. A.; LANA, R de P.; QUEIROZ, A. C. de; ASSIS, A. J. de; PEREIRA, M. L. A. Comportamento ingestivo de vacas leiteiras alimentadas com dietas à base de cana-de-açúcar ou silagem de milho. Revista Brasileira de Zootecnia, v. 33, n. 3, p. 723-728, 2004

MERTENS, D. R. Creating a system for meeting the fiber requirements of dairy cows. Journal of Dairy Science, v. 80, n. 7, p. 1463-1481, 1997.

MERTENS, D. R. Using fiber and carbohydrate analyses to formulate dairy rations. Journal of Animal Science, v.80, n.7, p.1463-1481, 1996.

NRC-NATIONAL RESEARCH COUNCIL. Nutrient Requirements of small ruminants. 1. ed. Washington: National Academy Press. 2006. 362p.

PEREIRA, E. S.; QUEIROZ, A. C.; PAULINO, M. F.; CECON, P. R.; VALADARES FILHO, S. C.; MIRANDA, L. F.; ARRUDA, A. M. V. de; 
FERNANDES, A. M.; CABRAL, L. da S. Fontes nitrogenadas e uso de Sacharomyces cereviseae em dietas à base de cana-de-açúcar para novilhos: Consumo, digestibilidade, balanço nitrogenado e parâmetros ruminais. Revista Brasileira de Zootecnia, v. 30, n. 2, p. 563-572, 2001.

PEREIRA, J. C.; CUNHA, D. de N. F. V. da; CECON, P. R.; FARIA, E. de S. Comportamento ingestivo e taxa de passagem de partículas em novilhas leiteiras de diferentes grupos genéticos submetidas a dietas com diferentes níveis de fibra. Revista Brasileira de Zootecnia, v. 36, n. 6, p. 2134-2142, 2007 (suplemento).

RIBEIRO JÚNIOR, J. I. Análise Estatística no SAEG Viçosa, UFV, 2001, 301p.

SAENZ, E. A. C. Modelagem da redução do tamanho de partículas na alimentação de ruminantes. Ciência e Agrotecnologia, v.29, n.4, p.886-893, 2005.

SANTOS, J.; CASTRO, A. L. A.; PAIVA, P. C. A.; BANYS, V. L. Efeito dos tratamentos físicos e químicos no resíduo de lixadeira do algodão. Ciência e Agrotecnologia, v. 28, n. 4, p. 919-923, 2004.

SILVA, D. J.; QUEIROZ, A. C. Análise de alimentos: métodos químicos e biológicos. Viçosa, MG: Universidade Federal de Viçosa, 2002. 235p.

SILVA, R. R.; MAGALHÃES, A. F.; CARVALHO, G. G. P.; SILVA, F. F. da; FRANCO, I. L.; NASCIMENTO, P. V.; BONOMO, P.; Comportamento ingestivo de novilhas mestiças de Holandês suplementadas em pastejo de Brachiaria decumbens. Aspectos metodológicos. Revista Electrónica de Veterinaria, v. 5, n. 10, p. 1-7, 2004.

TREVISAN, N. B.; QUADROS, F. L. F.; SILVA, A. C. F. da; BANDINELLI, D. G.; MARTINS, C. E. N. Efeito da estrutura de uma pastagem hibernal sobre o comportamento de pastejo de novilhos de corte. Revista Brasileira de Zootecnia, v. 34, n. 3, p. 774-780, 2005.

VAN SOEST, P. J. Nutritional ecology of the ruminant. 2.ed. Ithaca. Cornell University Press, 1994. 476p. 